\title{
Synthesis and Electropolymerization of Furan End-capped Dibenzothiophene/Dibenzofuran and Electrochromic Properties of Their Polymers
}

\author{
Hua Gu ${ }^{1+}$, Kaiwen Lin ${ }^{2+}$, Hongtao Liu ${ }^{3}$, Nannan Jian $^{3}$, Kai Qu ${ }^{3}$, Huimin Yu ${ }^{3}$, Jun Wei ${ }^{3}$, \\ Shuai Chen ${ }^{1,4, *}$ and Jingkun $\mathrm{Xu} \mathrm{u}^{1,4, *}$ \\ ${ }^{1}$ School of Pharmacy, Jiangxi Science \& Technology Normal University, Nanchang 330013, PR China \\ ${ }^{2}$ School of Materials Science and Engineering, South China University of Technology, Guangzhou \\ 510641, PR China \\ ${ }^{3}$ School of Chemistry \& Chemical Engineering, Jiangxi Science \& Technology Normal University, \\ Nanchang 330013, PR China; \\ ${ }^{4}$ Jiangxi Engineering Laboratory of Waterborne Coatings, Nanchang 330013, PR China \\ *E-mail: chenshuai@ms.xjb.ac.cn, xujingkun@jxstnu.edu.cn \\ \$ These authors contributed equally to this work.
}

doi: 10.20964/2017.06.29

Received: 20 January 2017 / Accepted: 18 April 2017 / Published: 12 May 2017

Two furan end-capped dibenzo five-membered ring monomers, 2,8-bis-(furan-2-yl)-dibenzothiophene (DBT-Fu) and 2,8-bis-(furan-2-yl)-dibenzofuran $(\mathrm{DBF}-\mathrm{Fu})$ were successfully synthesized via Stille couple reaction. Corresponding polymers, $\mathrm{P}(\mathrm{DBT}-\mathrm{Fu})$ and $\mathrm{P}(\mathrm{DBF}-\mathrm{Fu})$, were obtained by employed the electropolymerization. The surface morphology, electrochemical and optical properties of monomers and polymers were researched by cyclic voltammetry $(\mathrm{CV})$, scanning electron microscopy (SEM), and UV-via spectra method. Both polymers exhibited obvious color changes from neutral state to oxidation state (from green-yellow to dark grey for $\mathrm{P}(\mathrm{DBT}-\mathrm{Fu})$ and from beige to celadon for $\mathrm{P}(\mathrm{DBF}-\mathrm{Fu}))$.

Keywords: conducting polymers, furan, dibenzothiophene/furan, electropolymerization, electrochromism

\section{$\underline{\text { FULL TEXT }}$}

(C) 2017 The Authors. Published by ESG (www.electrochemsci.org). This article is an open access article distributed under the terms and conditions of the Creative Commons Attribution license (http://creativecommons.org/licenses/by/4.0/). 